\title{
Current Opportunities Within College Mental Health
}

\author{
Rachel C. Conrad ${ }^{1} \cdot$ Michelle Riba $^{2}$
}

Received: 14 November 2020 / Accepted: 2 August 2021 / Published online: 17 August 2021

(c) Academic Psychiatry 2021

College students are an increasingly high-risk and vulnerable psychiatric population [1, 2]. The ominous trends in this population are twofold: subclinical levels of stress and anxiety are growing across this population, while the proportion with a diagnosable psychiatric illness appears to be increasing. Stress, depression, anxiety, trauma, and suicidal ideation were rising before the pandemic uprooted their lives $[3,4]$. Most psychiatric disorders emerge prior to age 24, and psychiatric disorders are the leading cause of disabilityadjusted life-years among late adolescents and young adults in the USA [5, 6]. Suicide is the second most common cause of death among college-aged individuals, and the suicide rate among ages 15-19 increased 76\% from 2007 to 2017 in the USA [7].

The mental health of college students has rapidly deteriorated during the pandemic. Survey data collected in June 2020 by the Center for Disease Control (CDC) showed that the mental health of those ages 18 to 24 has been worse than any other age group during the pandemic, and alarmingly, $26 \%$ of respondents reported that they had seriously considered suicide during the past 30 days [8]. The Household Pulse Study shows that rates of anxiety and depression in college-age individuals have grown rapidly during the pandemic [9]. The COVID-19 Resilience Study for Young Adults (CARES) found that a high proportion of college students reported psychiatric symptoms [10]. An Active Minds survey of college students in April 2020 found that $80 \%$ of college students reported that the pandemic negatively impacted their mental health, and 55\% did not know where to go if they urgently needed mental health services [11].

College students are experiencing enormous stress and loss related to both the pandemic and other recent events. Students who were abruptly forced to move out of their

Rachel C. Conrad

Rconrad@bwh.harvard.edu

1 Brigham and Women's Hospital and Harvard Medical School, Boston, MA, USA

2 University of Michigan, Ann Arbor, MI, USA dormitories in the beginning of the pandemic have experienced persistent psychiatric symptoms [12]. Many students have been distressed by the murders of unarmed black Americans among other recent exposures of systemic racial injustice, which has compounded the stress, psychiatric risk, and mental health disparities that affect marginalized and under-represented college students [13, 14]. Amidst these myriad stressors, losses, uncertainties, and abrupt transitions, many college students lost access to mental health treatment, psychosocial support, and healthy coping strategies like social activities and exercise during the pandemic $[14,15]$.

Unfortunately, even prior to the pandemic, most college students reported that they do not know how to access mental health services $[16,17]$. Even among those with significant psychiatric symptoms, most did not receive psychiatric treatment $[18,19]$. The services available to college students are often fragmented, and little psychiatric research specifically accounts for the unique psychosocial and developmental circumstances of this population [20, 21].

\section{Current Challenges}

Although early screening and intervention among college students is critical to long-term prognosis and psycho-social outcomes, many colleges and universities lacked sufficient psychiatric resources prior to the pandemic, and the existing services are further stretched under our current circumstances [3, 22, 23]. Many students' access to mental health care has been disrupted by unexpected campus evacuations during the pandemic [14].

Tele-mental health is an expanding option that may increase mental health access for this population. However, manifold barriers to tele-mental health expansion remain and, further, vary by state [24]. Many students remain unable to access psychiatric treatment due to lack of payment parity for both mental health and telehealth services, laws and regulations that prevent physicians from practicing over state lines, and uncertainty whether mental health services 
provided by their school will continue during unanticipated disruptions. The most vulnerable students with multiple risk factors, such as low-income, first-generation, LGBTQ, BIPOC, and other underrepresented and marginalized students, may continue to fall through the cracks despite the increased availability of tele-mental health services [14].

College and university campuses have many structural models for the mental health treatment of college students $[21,25]$. Some colleges employ psychiatrists directly, and these psychiatrists may be incorporated into either a counseling center or health center [26]. Offering psychiatric services on campus may decrease barriers for students to initiate treatment, but challenges to this model include limited funding, disruptions during breaks in the academic year, and institutional policies capping sessions and restricting prescription of controlled substances such as stimulants medications for ADHD. When psychiatric services are not available on campus, students often receive treatment from private practice psychiatrists near their campus. Developing innovative models to target high-risk patients is challenging when psychiatrists are either practicing in a small private practice or working in a limited capacity on campus [27].

\section{Future Directions}

Academic departments of psychiatry are currently presented with an opportunity to invest in the subspecialty of college mental health. Developing college mental health subspecialties within academic psychiatry departments may increase both the psychiatric care available to college students today and the number of psychiatrists uniquely trained to work with this population in the future. Three factors may promote the timely and effective mental health treatment of college students: championing models based on interdisciplinary collaboration, providing psychiatric trainees clinical training opportunities in college mental health, and expanding research on evidence-based treatments specific to this population.

A robust and effective college mental health system requires timely access to evaluation, continuity of treatment, coordination across interventions, and multiple levels of care. Treatments must be provided through collaborative interdisciplinary teams. The contributions of patient advocacy, peer support, community health workers, social workers, and psychologists are critical. Working closely with advocacy organizations and peer support programs can de-stigmatize treatment and reach students who might otherwise not engage in treatment. Improving access, continuity, and coordination is most impactful for our most vulnerable patients. Given the variability in contexts between institutions, such as student populations, funding, and geographies, the implementation of these services may remain specific to the setting.

Psychiatrists practicing within an academic medical center may more easily facilitate referrals and collaborate with other specialties and subspecialties to address the needs of complex patients, such as collaborating with coordinated specialty care for patients with first-episode psychosis or neurology for patients with comorbid functional neurological disorders. Treatment from providers within one system is beneficial for patients with complex medical comorbidities as well. Transitions to higher levels of care and collaboration between inpatient and outpatient providers may be less burdensome when occurring within one institution. One academic psychiatry department may work with students from multiple small colleges or even affiliate with rural campuses via tele-mental health to increase access for underserved populations [22].

Training programs within the academic psychiatry departments may offer clinical training experiences in college mental health to medical students, residents, and fellows [26]. Residency and fellowship training programs can simultaneously stimulate trainees' interest in working with this population, increase college students' access to psychiatrists in the short-term, and launch the careers of psychiatrists who will thrive working in college mental health in the future. Expanding our teaching and training will build expertise and clinical excellence across our field.

Both the context of an academic environment and the presence of more trainees can stimulate scholarly inquiry, research, and publication within college mental health. The literature guiding the best practices in psychiatric treatment of college students is sparse and dominated by studies conducted at a single site or expert opinion rather than large, multi-site randomized control trials, the gold standard for evidence-based treatments [28]. Research is needed to investigate models of care and develop treatments specifically targeting college students. Developing college mental health within academic psychiatry departments may facilitate research endeavors [29]. Increasing research focused on college mental health will ultimately improve our understanding of this population and the quality of care offered to college students.

Many college students lacked access to mental health treatment prior to the pandemic, and the stressors associated with the pandemic have further increased the psychiatric risks and vulnerabilities within this population. Establishment of a college mental health subspecialty within academic psychiatry departments may help address these gaps by training psychiatrists in college mental health and promoting advancement within this field. 


\section{Declarations}

Disclosures On behalf of all authors, the corresponding author states that there is no conflict of interest.

\section{References}

1. LeViness P, Bershad, C., Gorman K, Braun L, Murray T. The Association for University and College Counseling Center Directors Annual Survey. 2018. [Accessed on 31 March 2021] Available from: https://www.aucccd.org/assets/documents/Survey/ 2018\%20AUCCCD\%20Survey-Public-June\%2012-FINAL.pdf

2. Watkins D, Hunt J, Eisenberg D. Increased demand for mental health services on college campuses: perspectives from administrators. Qual Soc Work. 2011;11:319-37.

3. Xiao H, Carney DM, Youn SJ, Janis RA, Castonguay LG, Hayes JA, et al. Are we in crisis? National mental health and treatment trends in college counseling centers. Psychol Serv. 2017;14(4):407-15.

4. Lattie EG, Lipson SK, Eisenberg D. Technology and college student mental health: challenges and opportunities. Front Psychiatry. 2019;10:246.

5. Kessler RC, Berglund P, Demler O, Jin R, Merikangas KR, Walters EE. Lifetime prevalence and age-of-onset distributions of DSM-IV disorders in the National Comorbidity Survey Replication. Arch Gen Psychiatry. 2005;62(6):593-602.

6. Gore FM, Bloem PJ, Patton GC, Ferguson J, Joseph V, Coffey C, et al. Global burden of disease in young people aged $10-24$ years: a systematic analysis. Lancet. 2011;377(9783):2093-102.

7. Curtin SC, Heron M. Death rates due to suicide and homicide among persons aged 10-24: United States, 2000-2017. NCHS Data Brief. 2019;352:1-8.

8. Czeisler M, Lane RI, Petrosky E, Wiley JF, Christensen A, Njai $\mathrm{R}$, et al. Mental health, substance use, and suicidal ideation during the COVID-19 pandemic - United States, June 24-30, 2020. MMWR Morb Mortal Wkly Rep. 2020;69(32):1049-57.

9. U.S. Census Bureau. Household Pulse Survey. 2020. [Accessed on 31 March 2021]. Available from: https://www.census.gov/progr ams-surveys/household-pulse-survey/data.htm

10. Liu CH, Stevens C, Conrad RC, Hahm HC. Evidence for elevated psychiatric distress, poor sleep, and quality of life concerns during the COVID-19 pandemic among U.S. young adults with suspected and reported psychiatric diagnoses. Psychiatry Res. 2020;292:113345.

11. Active Minds. Spring 2020 Student Survey. 2020. [Accessed on 31 March 2021]. Available from: https://www.activeminds.org/ studentsurvey/

12. Conrad RC, Hahm HC, Koire A, Pinder-Amaker S, Liu CH College student mental health risks during the COVID-19 pandemic: implications of campus relocation. J Psychiatr Res. 2021;136:117-26.

13. Liu CH, Stevens C, Wong SHM, Yasui M, Chen JA. The prevalence and predictors of mental health diagnoses and suicide among U.S. college students: implications for addressing disparities in service use. Depress Anxiety. 2019;36(1):8-17.

14. Liu CH, Pinder-Amaker S, Hahm HC, Chen JA. Priorities for addressing the impact of the COVID-19 pandemic on college student mental health. J Am Coll Health. 2020:1-3.
15. Conrad R, Rayala H, Menon M, Vora K. Universities' response to supporting mental health of college students during the COVID19 pandemic. Psychiatric Times. 2020. [Accessed on 31 March 2021]. Available from: https://www.psychiatrictimes.com/view/ universities-response-supporting-mental-health-college-studentsduring-covid-19-pandemic

16. Goodwin J, Behan L, Kelly P, McCarthy K, Horgan A. Helpseeking behaviors and mental well-being of first year undergraduate university students. Psychiatry Res. 2016;246:129-35.

17. Eisenberg D, Hunt J, Speer N. Help seeking for mental health on college campuses: review of evidence and next steps for research and practice. Harv Rev Psychiatry. 2012;20(4):222-32.

18. Garlow SJ, Rosenberg J, Moore JD, Haas AP, Koestner B, Hendin $\mathrm{H}$, et al. Depression, desperation, and suicidal ideation in college students: results from the American Foundation for Suicide Prevention College Screening Project at Emory University. Depress Anxiety. 2008;25(6):482-8.

19. Eisenberg D, Chung H. Adequacy of depression treatment among college students in the United States. Gen Hosp Psychiatry. 2012;34(3):213-20.

20. Kirsch DJ, Pinder-Amaker SL, Morse C, Ellison ML, Doerfler LA, Riba MB. Population-based initiatives in college mental health: students helping students to overcome obstacles. Curr Psychiatry Rep. 2014;16(12):525.

21. Downs N, Galles E, Skehan B, Lipson SK. Be true to our schoolsmodels of care in college mental health. Curr Psychiatry Rep. 2018;20(9):72.

22. Downs NS, Alderman T, Schneiber K, Swerdlow NR. Treat and teach our students well: college mental health and collaborative campus communities. Psychiatr Serv. 2016;67(9):957-63.

23. Sood AB, Cohen R. The Virginia Tech massacre: strategies and challenges for improving mental health policy on campus and beyond. New York, NY, US: Oxford University Press; 2015.

24. Conrad RC, Rayala H, Diamond R, Busch B, Kramer N. Expanding telemental health in response to the COVID-19 pandemic. Psychiatric Times [Internet]. 2020. [Accessed on 31 March 2021]. Available from: https://www.psychiatrictimes.com/view/expan ding-telemental-health-response-covid-19-pandemic.

25. Cornish PA, Berry G, Benton S, Barros-Gomes P, Johnson D, Ginsburg R, et al. Meeting the mental health needs of today's college student: reinventing services through Stepped Care 2.0. Psychol Serv. 2017;14(4):428-42.

26. Riba M, Kirsch D, Martel A, Goldsmith M. Preparing and training the college mental health workforce. Acad Psychiatry. 2015;39(5):498-502.

27. Morris MR, Feldpausch NI, Inga Eshelman MG, Bohle-Frankel BU. Recovering in place: creating campus models of care for the high-risk college student. Curr Psychiatry Rep. 2019;21(11):111.

28. Locke BD, Bieschke KJ, Castonguay LG, Hayes JA. The center for collegiate mental health: studying college student mental health through an innovative research infrastructure that brings science and practice together. Harv Rev Psychiatry. 2012;20(4):233-45.

29. Pinder-Amaker S. Introduction innovative and collaborative approaches to college student mental health challenges. Harv Rev Psychiatry. 2012;20(4):171-3.

Publisher's Note Springer Nature remains neutral with regard to jurisdictional claims in published maps and institutional affiliations. 